\title{
Clinical Applications of Ultrasound in Assessment of Follicle Development and Growth
}

\author{
V Vlaisavljević, M Došen \\ Department of Reproductive Medicine, Maribor Teaching Hospital, Maribor, Slovenia
}

\begin{abstract}
Monitoring of individual follicles during the menstrual cycle demonstrates in a noninvasive way the changes in their number and position during the early and the late follicular phase and the luteal phase. The differences in relations between the follicles near the dominant follicle can be demonstrated with the same technique using $3 \mathrm{D}$ reconstruction of the ovary.

An increased perifollicular blood flow can be measured in the perifollicular period using color and pulsed Doppler. Automated estimation of blood volume around the ovarian follicles brought a new concept to this area. Results confirm the observation that vascularity around the follicle is intense in the periovulatory period. The blood volume does not differ between follicles containing an oocyte and those with no oocyte in the aspirate, or a nonfertilizable oocyte. From our results we can hypothesize that those follicles containing oocytes able to produce pregnancy have a more uniform perifollicular vascular network .

Recognition of the follicle growth pattern has a prognostic value for the outcome of assisted reproduction methods. Follicular diameter and changes in growth patterns are more important than follicular wall thickness as parameters having an impact on clinical success.
\end{abstract}

Key words: Ultrasound, ovarian monitoring, follicle growth, natural cycle, controlled ovarian hyperstimulation, perifollicular vascularization, monitoring.

\section{INTRODUCTION}

Since the introduction of ultrasound imaging in medicine, the indications and the scope of application of this visualization technique in everyday practice of gynecology and obstetrics have been constantly widened. With new advancements in technology it is now possible to monitor even subtle physiological changes in the ovary.

Several recent reports review the use of ultrasonography in reproductive medicine in general, sonographic characteristics of reproductive organs during the normal menstrual cycle, the role of sonographic assessment in infertile patients and the possibility to use ultrasound as the only tool to monitor ovarian stimulation. ${ }^{1,2}$ This article describes various uses of ultrasound imaging in assisted reproductive technologies as the principal noninvasive technique for evaluation of the key process of ovarian function-the process of folliculogenesis. It reviews the ability of ultrasonography to predict the success of IVF cycles and monitor them.

Folliculogenesis is a constant process, which starts in the embryogenic period and ends with the disappearance of the last functional follicle in the period of menopause. The term "folliculogenesis" could be used in its broader meaning, when it is equal to the term "ovarian life cycle" which refers to all phases that a primordial germ cell has to pass to become the mature healthy oocyte that is subsequently fertilized. ${ }^{3-6}$

Histological studies of Gougeon and Lefèvre on primate and human ovarian tissue have established the useful morphological classification of follicles and have given a more detailed insight into the dynamics of follicle growth. ${ }^{7-10}$ According to morphometric criteria set by these authors, any given follicle can be classified into one of the eight classes of follicles and into two major developmental phases.

\section{THE ANTRAL PHASE OF FOLLICLE DEVELOPMENT AND FOLLICLE SELECTION}

During the course of sequential dramatic cellular proliferation and differentiation, primordial follicles of app. $60 \mu \mathrm{m}$ in diameter differentiate to intermediate, then to primary and eventually to mature secondary but still preantral follicles of $120 \mu \mathrm{m}$ in diameter, through the process called the slow growth phase. The development of a primordial to a full-grown secondary follicle requires app. 290 days or about 10 regular menstrual cycles (Fig. 1). ${ }^{11}$

The smallest early growing follicles lack an independent blood supply, but secondary follicles 80 to $100 \mu \mathrm{m}$ in diameter are served by one or two arterioles, terminating in an anastomotic network just outside the basal lamina. ${ }^{12}$ After the introduction of color and power Doppler ultrasonography it became possible to indirectly assess processes of angiogenesis, vessel maturation and vessel regression, which seem to be of key importance for selection of the dominant follicle, ovulation and corpus luteum formation and function. ${ }^{13-15}$ The development of an independent blood supply exposes the follicle directly to substances circulating in the blood. Secondary preantral follicles with a diameter of app. $120 \mu \mathrm{m}$ have multiple layers of 


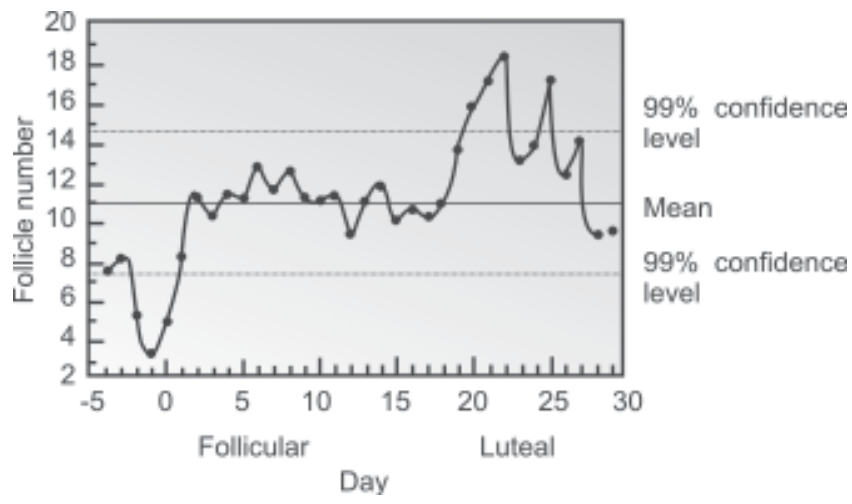

Fig. 1: Fluctuation in number of antral follicles in the ovulatory cycle (Gore et al. Hum Reprod 1995;10,2313-9)

granulose cells (GCs) which are coupled by gap junctions, thus forming the functional syncytium concerned with metabolic functions and chemical and electrical messaging pathways, thereby compensating for the otherwise avascular intrafollicular environment. ${ }^{11}$

At this point of development, the follicle begins to change into the antral follicle and after an 85-day journey becomes a follicle of preovulatory size. This antral phase of follicle development is typically divided into four stages. After the formation of the antrum ( $0.4 \mathrm{~mm}$ in diameter), the rate of follicular growth accelerates and follicle development enters the so-called accelerated growth phase. ${ }^{10,11}$

Healthy antral follicles measuring 2 to $5 \mathrm{~mm}$ that are present during the late luteal phase constitute the population from which the follicle destined to ovulate during the subsequent cycle will be selected. ${ }^{2-60}$ These follicles are commonly called recruited follicles, and the term recruitment is employed to indicate the process of constant follicle growth through which these follicles are provided. Their number in the late luteal phase is between three and 11 per ovary in women aged 24 to 33 years, ${ }^{16}$ and strongly decreases with increasing age. The process of follicular selection represents the final winnowing by atresia of the maturing, but not quite yet dominant follicular cohort, down to a size equal to the species-characteristic ovulatory quota. In our species, follicular selection is presumed to occur during the first five days of the cycle, at a time when the leading follicular diameter is 5 to $10 \mathrm{~mm} .{ }^{11}$ The follicle to be released during ovulation is the dominant follicle, and the term dominance refers to its status in comparison with other follicles recruited in the same cycle. It is presumed that the dominant follicle itself has the key role in regulating the size of the ovulatory quota. Generally, in humans one of the selected follicles becomes dominant about a week before ovulation-as early as days 5 to 7 of the cycle, at the time when the follicular diameter is app. $10 \mathrm{~mm}$. After attaining dominance, the follicle destined for ovulation grows with an almost uniform rate of 2 to

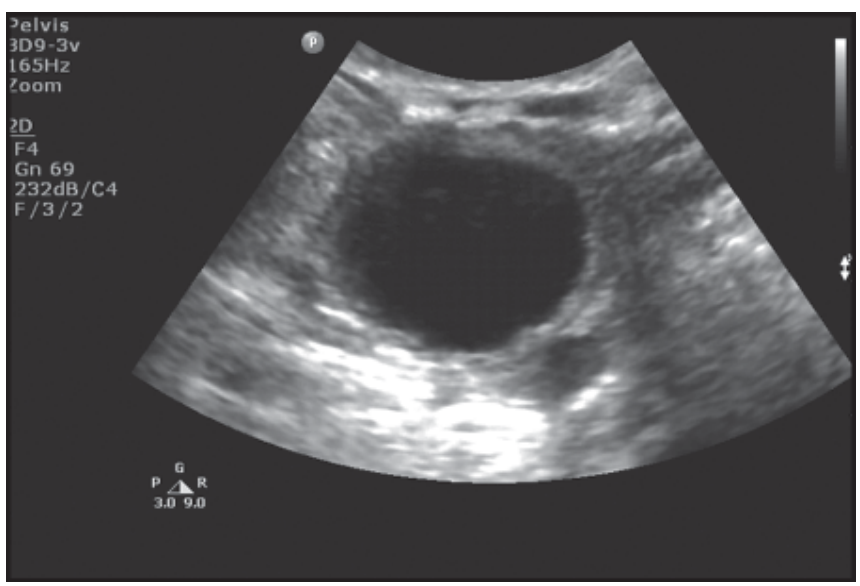

Fig. 2: Dominant follicle of preovulatory size in natural cycle. Thickness of follicle wall (granulosa) can be measured

$3 \mathrm{~mm}$ per day, until it reaches a mean diameter ranging from 17 to $27 \mathrm{~mm}$ just prior to ovulation (Fig. 2). ${ }^{10,17}$

The main pathway of blood supply to the mature follicle is through vascular network located along the inner border of the theca interna and from these vessels the transport of nutrients, oxygen, precursors of steroidogenesis and waste products goes through the avascular granulosa layer and to the oocyte by diffusion. As already mentioned, it is now feasible and easy to test hypotheses on a possible correlation between indices of perifollicular blood flow of the given preovulatory follicle and the quality of the oocyte, which is expressed indirectly through fertilization and pregnancy rates using color and power Doppler ultrasonography. These correlations have potentially great clinical importance in the prediction of cycle outcome in the in vitro fertilization (IVF) program.

Under the influence of the midcycle luteinizing hormone (LH surge, the dominant follicle undergoes dramatic transformations designed to effect further oocyte maturation as well as follicular rupture. Mechanically, ovulation consists of rapid follicular enlargement followed by protrusion of the follicle from the surface of the ovarian cortex. Finally, rupture of the follicle results in the extrusion of an oocyte-cumulus complex. Endoscopic visualization of the ovary around the time of ovulation has revealed that the rupture of the conical "stigma" on the surface of the protruding follicle is accompanied by gentle, rather than explosive, expulsion of the oocyte and antral fluid, suggesting that this process is not happening under high pressure. $^{5}$

After ovulation, rapid morphological transformation of the dominant follicle begins. Following expulsion of the oocyte, capillaries and fibroblasts from the surrounding stroma proliferate and penetrate the basal lamina. Concurrently, the mural granulosa cells undergo morphological changes collectively referred to as luteinization. Thus, luteinized 
granulosa cells (GCs), surrounding theca-interstitial cells and invading vasculature intermingle to give rise to the corpus luteum, a highly vascularized ephemeral endocrine gland, which is the major source of sex steroids in the postovulatory phase of the cycle. If pregnancy does not occur in the given cycle, after $14 \pm 2$ days the corpus luteum spontaneously regresses through the process called luteolysis, to be replaced at least five cycles later by an avascular scar referred to as the corpus albicans. In case of pregnancy, hCG secreted by the trophoblast maintains the viability and the ability of the corpus luteum to produce progesterone until the luteoplacental shift.

However, not all cycles are ovulatory. Nonovulatory cycles could be classified into three types: the cycle without dominant follicle development (a cohort of selectable follicles starts developing, but the dominant follicle does not emerge); the cycle with atretic dominant follicle (the dominant follicle develops, but becomes irregular, continues to grow until midcycle and then disorganizes without ovulation); and the cycle with luteinized unruptured follicle (the dominant follicle grows till midcycle, does not ovulate, the growth rate then doubles and irregular structures occur in the antrum).

\section{SONOGRAPHIC INDICES OF FOLLICLE GROWTH AND OVULATION}

Kratochwil et $a l^{18}$ were the first to describe and illustrate in 1972 that ovaries could be visualized by ultrasound and that follicles could also be identified. Following this initial report, the first systematic investigations with ultrasonographic demonstration of follicular development during spontaneous and stimulated cycles were performed in $1977 .{ }^{19}$ Since then, several authors have confirmed the initial observations and ultrasound provides a simple and noninvasive insight into the physiological changes during the menstrual cycle, also allowing accurate and reproducible investigations of follicular size, development and growth during the follicular phase. ${ }^{20-22}$

The ovary could be described as a relatively small, paired organ with a complex, mosaic-like, constantly changing structure, which has a central role in reproduction as it is the only source of ova and the main site of sex steroid hormone production in females. Despite the fact that ultrasonography has been introduced as a useful tool in clinical medicine and research since the 1970s, no studies have attempted to monitor and characterize the cohort of selectable antral follicles and their growth dynamics in vivo until the mid-nineties. ${ }^{23}$ The main reason for this was the absence of appropriately advanced ultrasound devices and inadequate computer modeling necessary for the evaluation of an organ such as the ovary, which does not have a rigidly fixed position in the pelvic cavity, but possesses an ever-changing histological structure and a daily changing structure and interfollicular position inside the ovary (Fig. 3). ${ }^{24}$

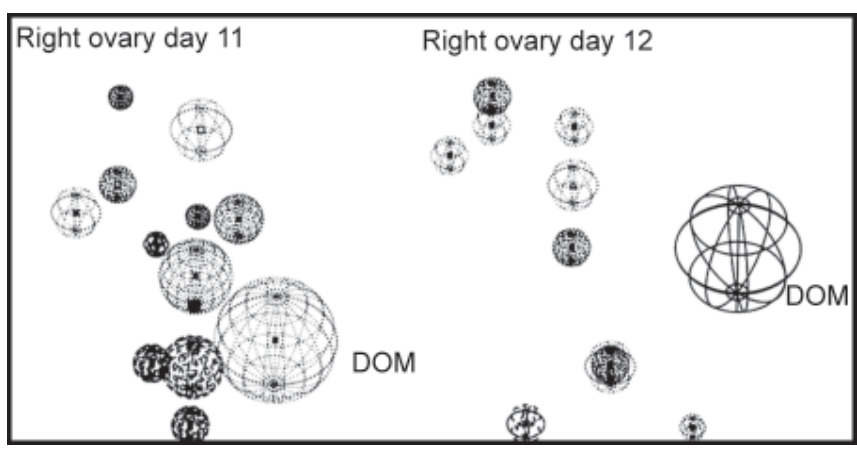

Fig. 3: Influence of dominant follicle on development of adjacent cohort (Gore et al. Hum Reprod 1997;12,22741-7)

For the purpose of reproducible and reliable data collection, it is common to take a follicular diameter of $\geq 2 \mathrm{~mm}$ as the lower visible limit. ${ }^{16,25}$ Secondary antral follicles, app. $2 \mathrm{~mm}$ in diameter, are the first follicular structures that may be visualized and investigated reliably by the common US device. The antral follicle count has clinical importance for estimating ovarian age and predicting its reactivity on controlled ovarian hyperstimulation. Antral follicle growth in the early follicular phase has clinical importance in appropriate timing of selected follicles for aspiration of immature human oocytes for in vitro maturation (IVM), prediction of cycle outcome in a natural cycle or controlled ovarian hyperstimulation $(\mathrm{COH})$ for IVF or intrauterine insemination (IUI). ${ }^{26-28}$

From the aspect of assisted reproduction, it is of critical importance to be able to predict the outcome of the monitored cycle (ovulatory $v s$ nonovulatory cycle) and to identify clinically applicable parameters of follicle quality, because one of the key factors that affects the quality of the oocyte, and thus indirectly the quality of the embryo and the outcome of pregnancy, is the quality of the follicle itself.

Before the study of Gore $e a^{24}$ in the population of healthy volunteers, there had been no previous studies, which had attempted to survey the entire visible antral follicle population of the ovary noninvasively (the exception are histological studies in humans ${ }^{7,29}$ and in cattle $\left.{ }^{30}\right)$.

Gore et al developed the method to identify, map, characterize and monitor growth, movement, positioning and interaction of individual follicles noninvasively using $2 \mathrm{D}$ ultrasound imaging along with computer modeling, which enabled 3D modeling of the ovary. They also introduced a set of visual criteria for the prediction of follicle status and cycle outcome (ovulatory vs nonovulatory) by investigating growth dynamics of the entire visible antral follicle population during natural, spontaneous cycles. ${ }^{23}$ In this study, ovulatory cycles were used as a reference for normality and these were characterized and compared with those cycles, which did not result in ovulation. They examined in detail the population of small follicles, restricting the analysis to the ovulatory cycles. An important finding was the drastic 
reduction of the antral follicle population at the end of the luteal phase, followed by a rapid increase in the population (new antral follicle growth). A new group of growing follicles may signal intense competition for dominance. These findings suggest that the population of follicles from which a dominant follicle arises is at the start of the new cycle and is preantral or early antral $(<2 \mathrm{~mm})$, sizes not detectable with ultrasonography. The authors were able to identify the dominant follicle before it became the largest follicle, and demonstrate that the first largest follicles observed were not usually the ultimate dominant follicles. The selection of the dominant ovulatory follicle occurs before day 5 th of the cycle, after day 5 th to 7 th its dominance becomes apparent by its continuously increased size by $2 \mathrm{~mm}$ per day (Figs 4 and 5).

Different growth patterns during the follicular phase of the cycle have different values in different types of stimulation protocols. The critical points for administration of hCG should differ in GnRH agonist and GnRH antagonist protocols. ${ }^{31}$ Some authors advocate different decisions for hCG administration in stimulation protocols with FSH and also in hMG. We believe that for a good clinical result of ART, in GnRH agonist downregulated cycles the diameter of the leading follicle must be bigger if $\mathrm{hMG}$ is used (18 to $19 \mathrm{~mm}$ ) than if recombinant FSH (17 to $18 \mathrm{~mm}$ ) is used. The same is true in GnRH antagonist downregulated cycles. Recording of follicle growth and the day when follicle selection started is important for $\mathrm{GnRh}$ antagonist administration, which is the main difference between so called "fix" and "flexible" antagonist protocols. ${ }^{34}$ In flexible protocols great importance is attributed to follicle growth dynamics. The antagonist should be administered at the moment when the follicles are selected from the cohort and they reach 12 to $14 \mathrm{~mm}$ in diameter.

Growth patterns in non-stimulated cycles are important, but only in relation with estradiol monitoring for the appropriate time of hCG administration. Unstimulated cycles monitored with ultrasound and the combination of serum E2 and urinary LH can produce an acceptable pregnancy rate after IVF and ICSI. $\mathrm{hCG}$ should be administered when serum E2 is $>0.49 \mathrm{nmol} / \mathrm{L}$ and follicle diameter at least $15 \mathrm{~mm}$. A higher pregnancy rate and lower cancellation rate can be obtained when hCG is applied in lower values of serum E2 and smaller follicle diameters, below the diameter believed to be of preovulatory size (Fig. 6). ${ }^{32}$

Visible characteristics of antral follicles mapped in the ovary, used by these authors for the prediction of the ultimate fate of the follicle, are: size (the largest diameter of the follicle), shape (round, oval, rectangular, triangular), echogenicity (high, medium, low) and antral edge quality (smooth, intermediate, rough). ${ }^{23}$ Subdominant follicles (antral follicles that would not gain dominance) had the least regular shape and antral edge, the smallest size by definition and the highest echogenicity in comparison to all monitored dominant follicles throughout the follicular phase. Ovulatory follicles (antral follicles that would

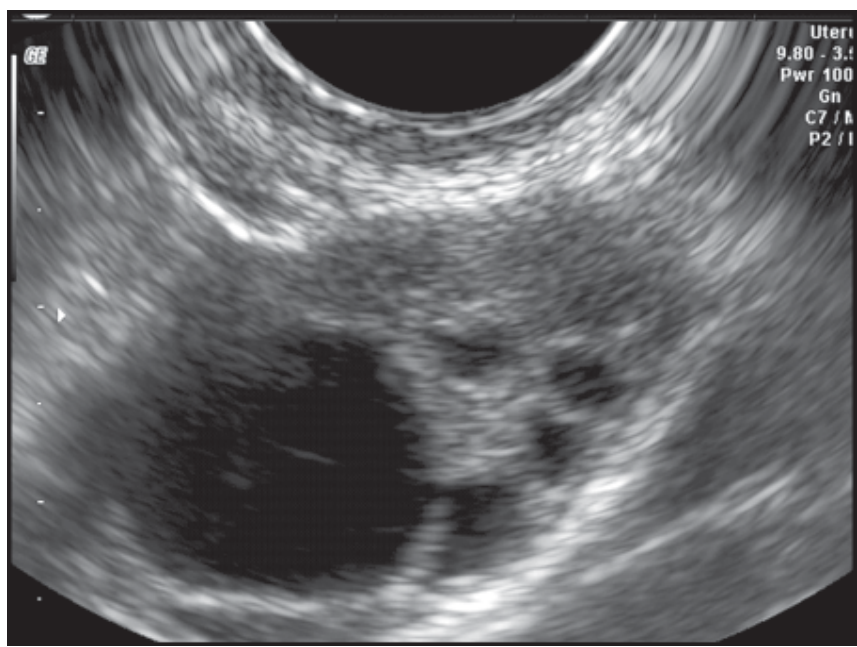

Fig. 4: Selection of dominant follicle in cohort of small follicles $10 \mathrm{~mm}$ in diameter

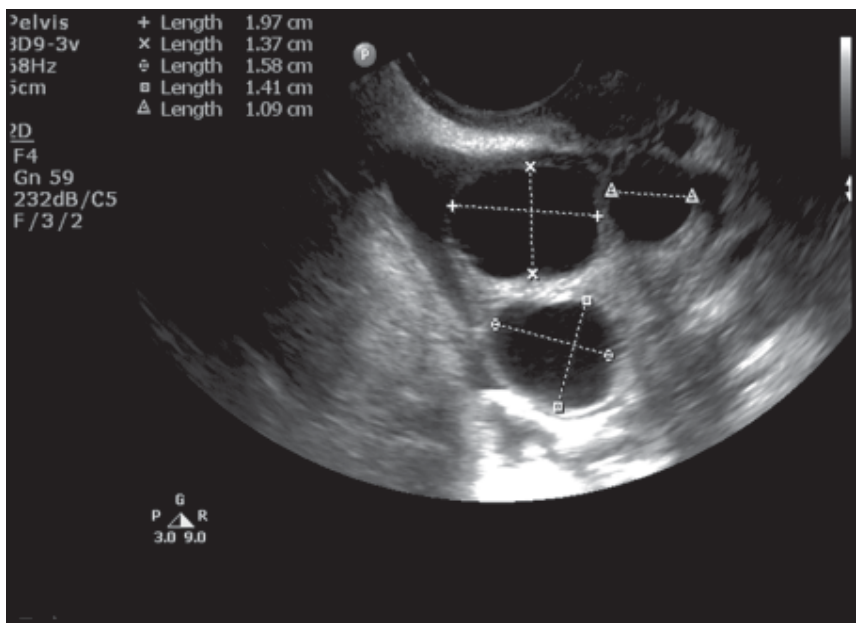

Fig. 5: Cohort of growing follicles after 8 days of controlled ovarian hyperstimulation: measurements of follicles diameter

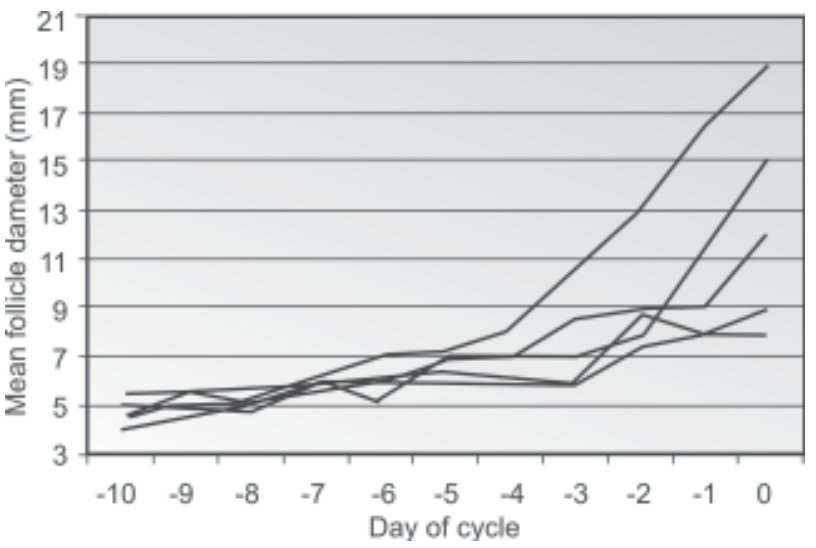

Fig. 6: Curves of follicular growth including two rapidly growing follicles and a cohort of slowly growing follicles. One follicle grew rapidly but a short time from day-2, the other from day-6 (most likely responsible for pregnancy) (Vlaisavljevic et al. Gynecol Perinatol 1991) 
ultimately ovulate) could be distinguished from atretic follicles by their round shape and from luteinized unruptured follicles by their middle range echogenicity. By the end of the follicular phase, their antral edge became smoother. Atretic dominant follicles had the least regular shape, but they were the largest follicles in the early follicular phase. Their antral edge then became more irregular, while their echogenicity remained at the same level. Luteinized unruptured follicles (dominant follicles that would not ovulate, but would become luteinized) could be distinguished from other dominant follicles throughout the follicular phase by their regular shape, smooth antral edge and very low echogenicity.

According to these authors, the most important distinguishing features between ovulatory follicles and LUFs on the one side, and atretic dominant follicles on the other side, are: in the early follicular phase, both follicle types were the roundest among all selectable follicles and in the mid-follicular phase both were roundest and largest. By the late follicular phase, ovulatory follicles and LUFs differ from each other by their echogenicity (middle range vs low echogenicity). Atretic dominant follicles were the least regular in shape and antral edge.

By distinguishing antral follicles from those identified later on as dominant and those where atresia will occur in the next few days of development (challenger follicles), ultrasound offers the possibility of new information about the "behavior" of such cohorts of antral follicles (> $6 \mathrm{~mm}$ in diameter). ${ }^{23,24}$ The results of this study showed that antral follicle development was not restricted to a particular location in the ovary. The apparent randomization of location may provide a developmental advantage for the follicles. Using the comparison of the dayby-day ultrasonographic scan with the 3D model of the same ovary, it was established that the dominant follicles subsequently appeared to reduce the number of neighboring challenger follicles. This result suggests that paracrine secretion of the dominant follicle was the source for the localized effect providing increased nutrient level and space at the critical growth stage for dominant follicles. The dominant follicle has a linear growth rate between 1.4 and $2.2 \mathrm{~mm}$ per day until the day of the LH peak, at the time of the LH surge it measures between 18.1 and $22.6 \mathrm{~mm}$. After the peak, growth increases very quickly. ${ }^{26}$

Sequential ultrasonographic follow-up of follicle growth was published by Nayudu et al. ${ }^{27}$ The first US scan was done between day 8 th and day 10th of the cycle to determine whether a pattern of growth is common in the cohort of retrieved follicles related to conception. They observed 107 stimulated cycles and constructed individual profiles for each follicle. Parameters of follicle growth pattern have been suggested to be associated with or predictive of follicle quality.

The growth rate of $2 \mathrm{~mm}$ per day quoted generally is certainly too low. In our previous study we analyzed the growth rate in 101 IUI cycles. In pregnant patients a rapid daily follicular growth rate (> $2.3 \mathrm{~mm} /$ day) was present more frequently $(83.3 \%)$ than in nonconceivers where a fast daily growing rate was observed in only $18.1 \% .^{28}$

Early angiographic studies carried out by color Doppler ultrasonography in natural cycles showed that the main characteristics of blood flow in perifollicular tissue of nondominant growing antral follicles were low velocity and high resistance. ${ }^{33}$

\section{SONOGRAPHIC INDICES OF OVULATION}

The preovulatory follicle undergoes great changes during the last seven days preceding ovulation: an increase in size and granulosa cell thickness, and increased perifollicular vascularization in the theca layer. Changes in follicular diameter and volume are an ultrasonographic manifestation of changes in the granulosa cell compartment initiated by LH. This echographic finding reflects the echographic manifestation of physiologic reactivity of granulosa cells (intensive division) and the increase of follicular fluid, which correspond only to an increase of serum transudate through the granulosa. The thickness of the granulosa wall is in direct relation with health or atresia of the follicle, not only during the follicular phase but also shortly before ovulation. A thin follicular wall is suggestive of an atretic follicle.

Several ultrasonographic parameters, which are indicative of ovulation, have been reviewed for sensitivity and specificity in the study of Ecochard et al. ${ }^{34}$ If we accept the definition of the day of ovulation as the day of maximal follicular growth or as the day of follicle rupture, ${ }^{35}$ the key sonographic indices of ovulation are: disappearance of or sudden decrease in follicle size (the most frequent sign of ovulation with the sensitivity of $84 \%$ ), appearance of ultrasonic echoes in the follicle (the sign which is not quite reliable, because its value rises both before and after ovulation - the proportion of cycles with echoes in the follicle increases gradually during the three days preceding ovulation, but there is also a sharp increase of this proportion on the first postovulatory day), irregularity of follicle walls (sensitivity of this sign, which is present in almost $70 \%$ of cycles, is much higher than that of the appearance of intrafollicular echoes), free fluid in the pouch of Douglas (despite the fact that free fluid could be seen in the cul-de-sac during all phases of the cycle, it is a rare finding ( 3 to $11 \%$ of the cycles) during the preovulatory phase, but much more common (77\%) on the day of ovulation).

Angiographic studies of preovulatory follicles using 2D color Doppler ultrasound device show that the perifollicular blood flow velocities gradually increase in the periovulatory period. This increase starts approximately 29 hours before ovulation and continues for at least 72 hours later, and that may be the consequence of the penetration of blood vessels into the granulosa cell layer. In the same period, the pulsatility index (PI) remains relatively constant, and the vascular resistance 
index in perifollicular vessels shows low to moderate values. These findings suggest a marked increase in blood flow at the periovulatory period.$^{13,36,37}$ Also, a marked increase in blood flow at the base and a decrease in blood flow at the apex of the follicle is noted during follicle growth. This feature of perifollicular circulation may be of essential importance for the later release of the mature oocyte. ${ }^{38}$

The study of Jarvela et $a l^{39}$ was the first one to utilize both 3D sonography and power Doppler for the evaluation of vascularization and blood flow during the late follicular phase in women with normal ovulation. No differences were detected in the values of vascularization indices between the dominant and the nondominant ovaries, suggesting that the mean blood flow in both ovaries was equal. This is the consequence of two facts: the dominant ovary has a larger volume than the nondominant one as a direct result of the existence of the dominant follicle; and vascularization is increased in the dominant ovary compared to the nondominant one. Accordingly, the ratio of the amount of vascularization per volume remains constant and similar to that in the nondominant ovary in the late follicular phase of the cycle.

An increased perifollicular blood flow can be measured in the perifollicular period using color and pulsed Doppler. Automated estimation of blood volume around the ovarian follicles brought a new concept to this area. Our results confirm the observation that vascularity around the follicle is intense in the periovulatory period. The blood volume does not differ between follicles containing an oocyte and those with no oocyte in the aspirate, or a nonfertilizable oocyte. From our results we can hypothesize that those follicles containing oocytes able to produce pregnancy have a more uniform perifollicular vascular network. $^{40}$

\section{SONOGRAPHY IN THE PREDICTION OF SUCCESS OF IVF CYCLES}

To improve the pregnancy rate with IVF cycles, it is important to identify the factors that are able to predict the outcome of the monitored cycle and the success of the IVF procedure. In a series of studies, a great number of nonsonographic variables with possible predictive values have been investigated and classified into three large categories: maternal age, ovarian reserve, and past reproductive history.

Recognition of the follicle growth pattern has a prognostic value for the outcome of assisted reproduction methods. Follicular diameter and changes in growth patterns are more important than follicular wall thickness as parameters having an impact on clinical success. Measurements of intrafollicular levels of estradiol in aspirated follicular fluid of the dominant follicle have no clinical value in selecting follicles with a more active granulosa cell compartment related to fertilization or pregnancy after IVF.
Ultrasonographic parameters as predictors of IVF success have also been investigated. Introduction of color Doppler, power Doppler and 3D ultrasound devices have allowed research of a very wide spectrum of potential predictors. Now it is easier to carry out basic morphometric analyses of reproductive organs; better resolution of the picture, computer modeling and data storage enable investigation of smaller structures and processes; studies of blood flow (even blood flow in quite small vessels, such as the vascular network of the inner border of the theca interna) are a part of everyday practice. ${ }^{40}$

Lately much attention has been paid to sonographic studies of perifollicular blood flow and its importance in the process of oocyte maturation, i.e. as a possible factor influencing oocyte quality. Various independent lines of evidence support the conduction of these studies. Experiments on animals have shown that perifollicular vascular network development is one of the factors with potential influence on selection and maturation of the dominant follicle. ${ }^{41}$ Autoradiographic and histological studies have also demonstrated that one of the important features of follicular growth is an increase in the perifollicular capillary network volume. ${ }^{42}$ Another strong reason for conducting the studies of correlation between perifollicular blood flow and the quality of the oocyte was found in the implications that more than $25 \%$ of normal-appearing oocytes obtained for IVF are affected by developmental lethal chromosomal abnormalities. ${ }^{43}$ Those abnormalities are the result of cumulative effects of various noxious environmental influences on oocytes over the entire lifetime of the patient. One possible mechanism through which those noxious influences affect the quality of the oocyte is a hypoxic intrafollicular environment with a low metabolism rate and low $\mathrm{pH}$ that could influence the organization and stability of the meiotic spindle. Hypoxia could be a result of insufficient perifollicular vascular network of the growing and/or preovulatory follicle. ${ }^{44}$

Sonographic parameters with predictive value on cycle outcome have been tested mostly for stimulated cycles, and only few studies are focused exclusively on natural cycles.

\section{ULTRASOUND MONITORING IN STIMULATED CYCLES}

Studies of possible sonographic predictors of cycle outcome and success of ART procedures carried out so far were done almost exclusively in stimulated cycles. As was mentioned for natural cycles, traditionally, the age of the patient is the single most useful non-sonographic parameter for prediction of ovarian response, followed by the early follicular phase serum FSH levels. ${ }^{45-48}$ The most important ultrasonographic parameters with potential predictive value for ovarian response to a stimulation protocol are: antral follicle number, ovarian volume, and ovarian stromal blood flow. 


\section{Ovarian Volume}

Ovarian volume is the parameter most easily assessed compared to the others. Using transvaginal sonography, Syrop et al ${ }^{49}$ showed that ovarian volume has predictive importance for ovarian response to ovulation induction. Later, Lass et al ${ }^{50}$ indicated a strong association between ovarian volume and ovarian reserve, and they recommended that this parameter should be measured in all patients prior to IVF. Their results showed that small ovaries were associated with poor response to human menopausal gonadotropin and with a high cancellation rate during IVF. Among the first who used 3D ultrasound as an adjunct to conventional markers of ovarian reserve, Pellicer et $a l^{51}$ failed to show a statistically significant difference in ovarian volume between low responders and controls on day $3 \mathrm{rd}$ of the cycle. In the study, of the influence of aging on morphometric parameters of the ovary and FSH levels in infertile women, Sharara and $\mathrm{McClamrok}^{52}$ found a statistically significant correlation between age and FSH levels and between FSH levels and the number of antral follicles, but not between age and ovarian volume or between FSH levels and ovarian volume. In a later study the same authors ${ }^{53}$ observed that in a group of IVF women with small ovarian volumes $\left(<3 \mathrm{~cm}^{3}\right)$ the implantation and pregnancy rates could be comparable to those with larger ovarian volumes if they were treated with higher doses of gonadotropins. Kupesic et $a l^{54}$ showed the number of retrieved oocytes and the conception rate to be higher in patients with a greater ovarian volume and a greater ovarian vascularity, but these parameters were not independent from the total antral follicle number. Despite its promising predictive importance at the beginning, it is nowadays accepted that ovarian volume has a limited predictive value, because it is not an independent factor in the prediction of cycle outcome.

A possible important use of the measurement of ovarian volume and stromal area is in the differentiation between multifollicular and polycystic ovaries. ${ }^{55}$ The ovarian ultrasound appearance of follicles of various sizes scattered throughout an ovary with no excess of medullary stroma should be referred to as a multicystic ovary (MCO). The polycystic ovary (PCO) has a typical visual appearance and can be recognized as an almost spherical ovary with more than 10 follicles (with mean diameter under $9 \mathrm{~mm}$ ) grouped along its surface (necklace sign). The ovarian stromal area is increased in size (sandstorm sign), which makes the ovary usually_-but not always_-larger than normal. The multifollicular ovary is of normal size, or slightly enlarged, and it has six or more follicles (with a diameter of 4 to $10 \mathrm{~mm}$ ). The stromal area is not increased and the follicles are not located along the ovarian surface, but are dispersed within the ovary. ${ }^{56}$ Ovarian stromal blood flow was proven to be significantly higher in polycystic ovaries, so it has been suggested that this parameter could be used as a possible marker for polycystic ovaries. ${ }^{57}$ It should be emphasized, however, that the polycystic ovary is a sign, not a disease, and a single pathognomonic marker (either biochemical or ultrasonographic) of this syndrome, in which anovulation plays a central role, does not exist. The selection of a specific criterion to base this diagnosis on will inevitably fail to include many patients with this problem, which has a broad spectrum of manifestations. This is applicable to the diagnostic use of ultrasonographic criteria as well. ${ }^{58}$ It is important to note that not all women with the endocrine syndrome of PCOS have polycystic appearing ovaries, and that polycystic ovaries alone should not be viewed as synonymous with polycystic ovary syndrome. In the new ESHRE/ASRM classification of PCOS ultrasound, for the first time US plays a crucial role in the diagnosis of PCOS, which includes estimation of ovarian volume, echographic visualization of stroma, and antral follicle count (Fig. 7). ${ }^{58}$

Polycystic ovaries appear to be an independent risk factor for ovarian hyperstimulation syndrome after ovulation induction; therefore, it may make clinical sense to document the morphology of the ovary in infertile patients seeking ovulation induction.

\section{Antral Follicle Numbers}

The first report on the usefulness of the number of antral follicles in predicting ovarian response showed that the number of antral follicles present before stimulation was a better predictor than ovarian volume or age alone. ${ }^{59}$ In this study, the number of antral follicles correlated with the number of retrieved oocytes, and ovarian volume correlated with the number of antral follicles, but not with the number of retrieved oocytes. The results of Chang et $a l^{60}$ confirmed those from the previous study-in the cycles with less than three antral follicles before stimulation, a higher chance of cycle cancellation, a lower $\mathrm{E}_{2}$ levels and a need for higher doses of gonadotropins were reported. Another

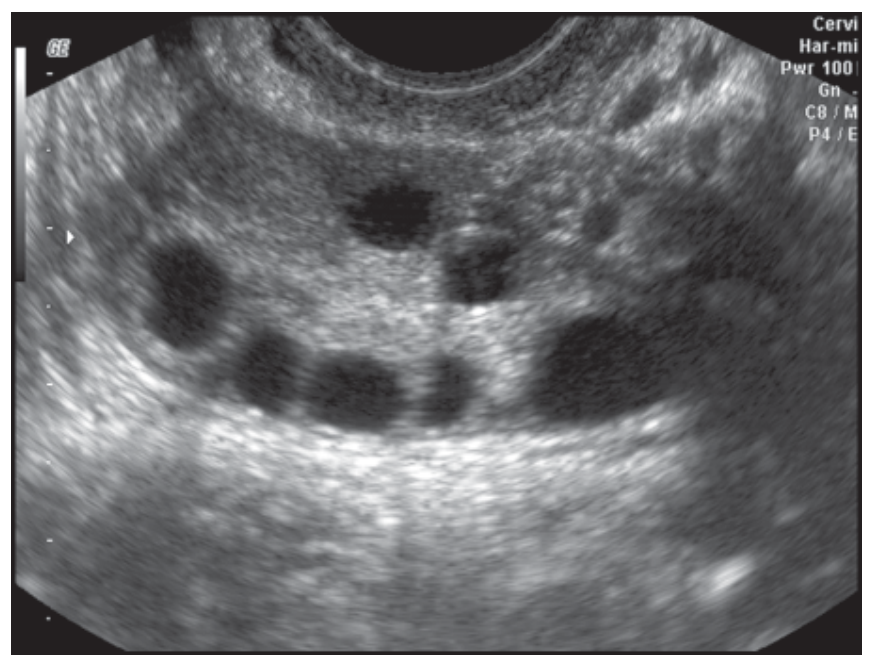

Fig. 7: PCOS ovary. Numerous follicles between 4 and $7 \mathrm{~mm}$ in diameter 
study ${ }^{49}$ in a group of women with proven natural fertility, which evaluated antral follicle number in relation to age using transvaginal ultrasonography, demonstrated that this sonographic parameter showed the clearest correlation with age, with the mean annual decline of near $5 \%$ before the age of 37 , compared with almost $12 \%$ thereafter. In the recent study of Kupesic et al, ${ }^{61}$ in patients with normal basal serum FSH levels the total antral follicle number was the most important predictor of ovarian response and IVF outcome. Ovarian stromal flow index (FI) was another parameter of clear clinical predictive importance. At present it is widely accepted that the total number of small antral follicles in both ovaries is the most important predictive parameter of cycle outcome. It is strongly related to reproductive age and can reflect the size of the remaining follicle pool well.

\section{Ovarian Stromal Blood Flow}

There are several strong reasons to focus attention on the parameters of ovarian stromal blood flow. The parameters which have been most commonly used and thoroughly investigated are peak systolic velocity (PSV), pulsatility index (PI), resistance index (RI) and, lately, vascularization index (VI), flow index (FI), vascularization flow index (VFI). Zaidi et al demonstrated the relationship between ovarian stromal blood flow velocity (expressed through PSV in the group of poor responders) and ovarian response to stimulation. ${ }^{57}$ Later on, Engmann et al ${ }^{62}$ demonstrated that the mean ovarian stromal PSV on the day of pituitary suppression was a better predictor of cycle outcome in the population of patients with normal basal FSH. Nagrund et $a l^{63}$ discovered significantly higher PSV of follicles in the cycles ending with fertilization. In this study, PSV $>10 \mathrm{~cm} / \mathrm{s}$ signified a $70 \%$ probability for the development of a high-quality embryo in the IVF procedure. It should be noted that some studies of mean values for follicular $\mathrm{PSV}^{64}$ and of maximum PSV from serial monitoring ${ }^{65}$ showed no differences in values between conception and nonconception cycles. Other studies, in which individual follicles, oocytes and preimplantation embryos were investigated, revealed a significant difference in PSV in conception vs nonconception cycles. ${ }^{66}$ At first sight these results seem confusing, but they are a logical consequence of the fact that it is the individual follicle/oocyte and not the cohort of selected follicles that determines a successful outcome of the cycle.

Ovarian stromal vessels are thin and torturous and it is impossible to obtain the angle between the ultrasound beam and the intraovarian vessel accurately. This represents the potential limitation of PSV as the predictor of cycle outcome, because it leads to more subjective measurements and depends on the experience of the examiner, who should search for the highest velocity in the intraovarian vessels. In the period preceding the introduction of the new generation of more powerful ultrasound devices and the new set of sonographic parameters of blood flow (FI and VFI), the approximation that at least one vessel in the vascular bed would be located at the appropriate angle was acceptable. ${ }^{36,67,68}$ At present, according to some authors, ${ }^{61}$ using PSV as the main predictive parameter has too many shortcomings and it was replaced by parameters independent of the examiner's experience.

Using a 3D and power Doppler ultrasound devices in the study that evaluated the predictive value of antral follicle number, total ovarian volume, total stromal area and mean flow index (FI) for ovarian response and IVF outcome, Kupesic et al $l^{61}$ found that antral follicle number was the most important predictor, followed by ovarian stromal FI, while other examined factors were less predictive. These authors also concluded that 3D ultrasound enables more objective assessment of ovarian morphology and analysis of ovarian stromal blood flow, shortens the time of examination and increases the patient's comfort. In another recent study, Järvelä et $a l^{69}$ measured the vascularization index (VI), flow index (FI) and vascularization flow index (VFI) in 45 patients after pituitary down-regulation and stimulation with gonadotropins, in order to evaluate whether $3 \mathrm{D}$ power Doppler predicts ovarian response to stimulation in IVF. The number of retrieved oocytes correlated with the antral follicle number and ovarian volume, but not with VI, FI and VFI. It was shown that all three indices of vascularity were significantly increased during gonadotropin stimulation in the group of normal responders compared to the low ovarian reserve group, but this was related to the antral follicle number, which emphasized the importance of this marker as an independent variable (Figs 8 and 9).

\section{ULTRASOUND MONITORING IN NATURAL CYCLES}

The term "natural cycle" is used to describe spontaneous, unstimulated cycles from which oocytes are recovered for IVF

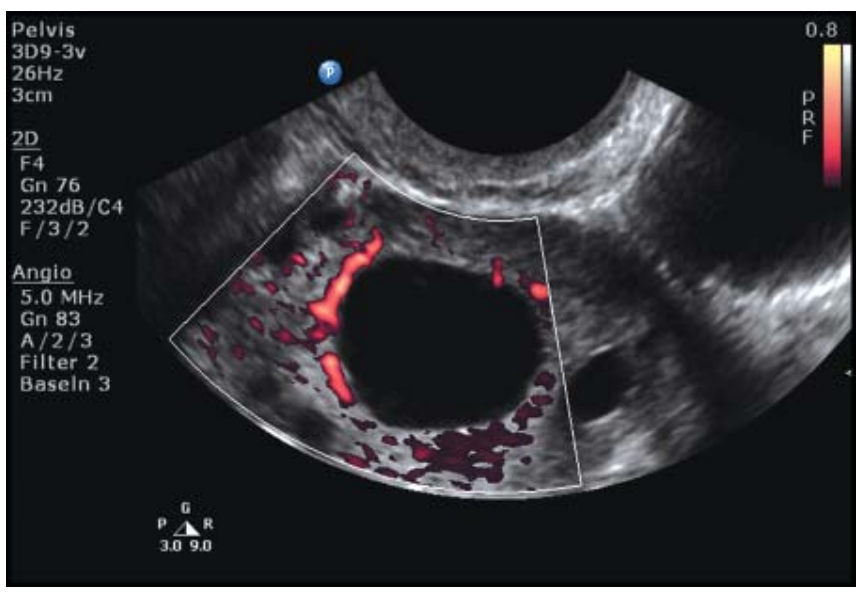

Fig. 8: Perifollicular blood flow of single dominant follicle from natural cycle 


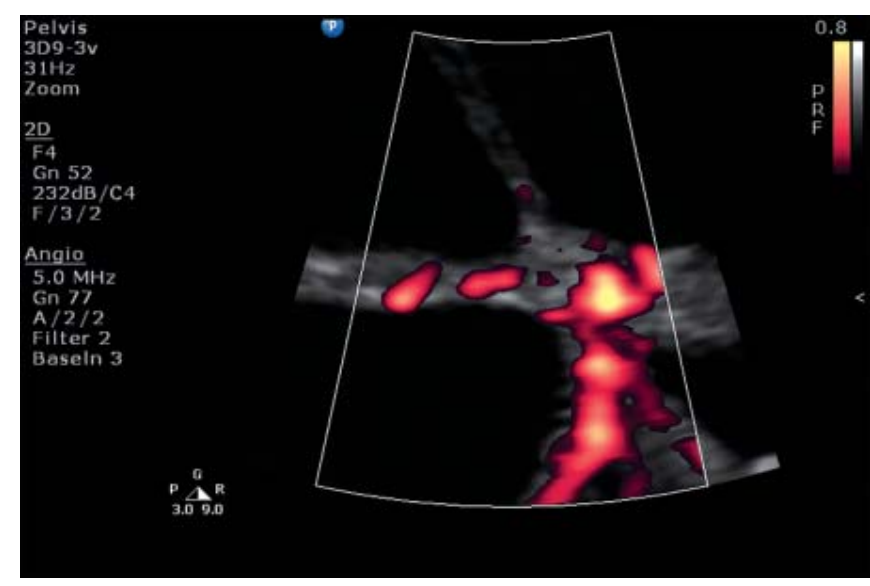

Fig. 9: Vascularization of interfollicular septa (theca) in ovary stimulated with gonadotropins

after human chorionic gonadotropin (hCG) administration to replace and precede the natural luteinizing hormone $(\mathrm{LH})$ surge. ${ }^{70}$ IVF in natural cycles is an accepted method for treatment of infertility in selected patients, ${ }^{71,72}$ and their monitoring and clinical application has greatly extended our knowledge of human reproductive physiology. Despite the fact that those cycles have several advantages over stimulated ones, high failure rate at each step in the process and the unacceptably low delivery rate per oocyte recovery attempt compared to stimulated cycles are the main reasons why they are not widely used in IVF programs. $^{73}$

In evaluating follicular maturity in unstimulated cycles prior to hCG application, some authors give precedence to adequate serum $\mathrm{E}_{2}$ level over ultrasonographic measurement of follicular diameter. According to Foulot et $a l^{74}$ a follicle is mature when the follicle diameter exceeds $18 \mathrm{~mm}$ and serum estradiol exceeds $0.66 \mathrm{nmol} / \mathrm{L}$. Despite the fact that the value of combining the criteria of maximum follicular diameter and serum E2 level is evident, it has not yet been agreed which E2 level is closest to the optimum. These values vary between $1.1 \mathrm{nmol} / \mathrm{L},{ }^{75} 0.73$ to $1.1 \mathrm{nmol} / \mathrm{L},{ }^{76} 0.88 \mathrm{nmol} / \mathrm{L},{ }^{77} 0.50 \mathrm{nmol} / \mathrm{L}^{78}$ and $0.40 \mathrm{nmol} / \mathrm{L}^{79}$

In IVF programs where single follicle development in natural cycles was monitored by ultrasound only, the main problem was an unwanted spontaneous LH surge. Even when folliculometry was repeated every second day until the follicle reached a diameter of $16 \mathrm{~mm}$ and then carried out daily, when the average diameter of the dominant follicle reached $18 \mathrm{~mm}$, in $40 \%$ of cycles a spontaneous LH surge or ovulation was observed before oocyte pick-up. ${ }^{72}$

In the more physiologic approach suggested by Paulson et al, ${ }^{70}$ ultrasound monitoring of follicle development was started on day 3rd of the menstrual cycle. Folliculometry was then carried out every second day. Three follicle diameters were measured and the mean value was taken into consideration.
When the follicle reached the average diameter of $16 \mathrm{~mm}$, folliculometry was done daily. At this diameter, the determination of the estradiol level, and of the presence of LH in urine also started. Decisions regarding the application of hCG were made on the basis of criteria which are a combination of serum estradiol levels and mean follicle diameters. On the day the mean follicle reached a diameter of $18 \mathrm{~mm}$ and serum $\mathrm{E}_{2}$ a level of $0.91 \mathrm{nmol} /$ $\mathrm{L}, \mathrm{hCG}$ was given. In cases where the $\mathrm{E} 2$ level did not reach 0.91 $\mathrm{nmol} / \mathrm{L}$ while the mean follicle diameter reached $20 \mathrm{~mm}, \mathrm{hCG}$ was given when $\mathrm{E} 2$ reached at least $0.73 \mathrm{nmol} / \mathrm{L}$. In cases where E2 reached higher values than $1.1 \mathrm{nmol} / \mathrm{L}$ before the follicle diameter reached $18 \mathrm{~mm}$, hCG was administered only in case the follicle diameter reached at least $16 \mathrm{~mm} .{ }^{70}$ Even in such a flexible approach spontaneous ovulation was not eliminated.

Based on the results of our previous study, ${ }^{32}$ we modified the criteria for hCG application to those when the follicle reaches at least $15 \mathrm{~mm}$ in mean diameter and serum E2 is $0.49 \mathrm{nmol} / \mathrm{L}$. Despite such low values of serum E2 and the small mean follicle diameter, the aspirated oocytes were suitable for IVF/ICSI with similar fertilization rate and implantation rate of cleavage embryos with spontaneous LH surge or ovulation before OPU in less than $10 \%$ of cases.

Studies of perifollicular blood flow in small groups of natural cycles demonstrated an increase in peak systolic velocity (PSV) and a tendency of the pulsatility index (PI) to decrease. ${ }^{36,67,81}$ In other studies the authors report a statistically significant increase in PSV in perifollicular vessels, but no change in PI. ${ }^{36,67}$ In the later study of GavriæLovrec et $a l,{ }^{82}$ carried out in a larger group (a total of 178 cycles) of unstimulated cycles, no statistically significant increase in PSV between fertilization and non-fertilization cycles was demonstrated, but rather a decrease in PI and resistance index (RI) was shown. The study investigated the usefulness of the percentage of blood volume showing a flow signal (VFS) inside a $5 \mathrm{~mm}$ capsule of perifollicular tissue of the dominant preovulatory follicle as a predictor of the outcome of unstimulated IVF/ICSI cycles. ${ }^{76}$ The more uniform vascular network in the capsule was a more frequent finding than average in cycles with implantation compared to nonimplantation cycles, but this difference only reached borderline statistical significance (Figs 10 and 11).

At this stage of our knowledge, the results from the studies of the predictive value of sonographic indices in natural cycles are controversial, so quantitative Doppler measurement of perifollicular blood flow is of limited value as a parameter for decision making in IVF procedures with natural cycles.

\section{ULTRASOUND AS THE ONLY MONITORING TOOL FOR ASSISTED REPRODUCTION}

Before ultrasonography became a routine method for monitoring of follicle development, this role was attributed to serum estradiol $\left(\mathrm{E}_{2}\right)$. After it was demonstrated that a direct correlation 


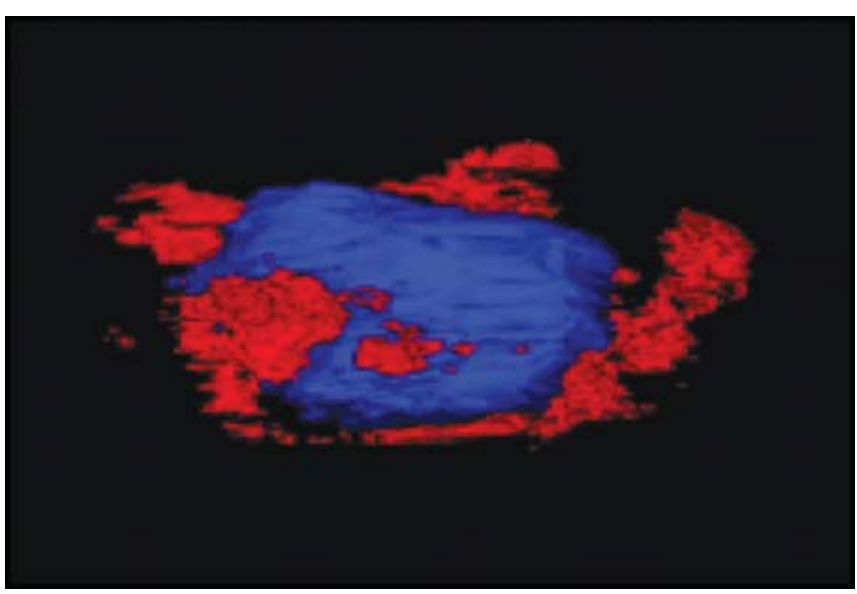

Fig. 10: Compartments of follicular fluid and perifollicular vessels

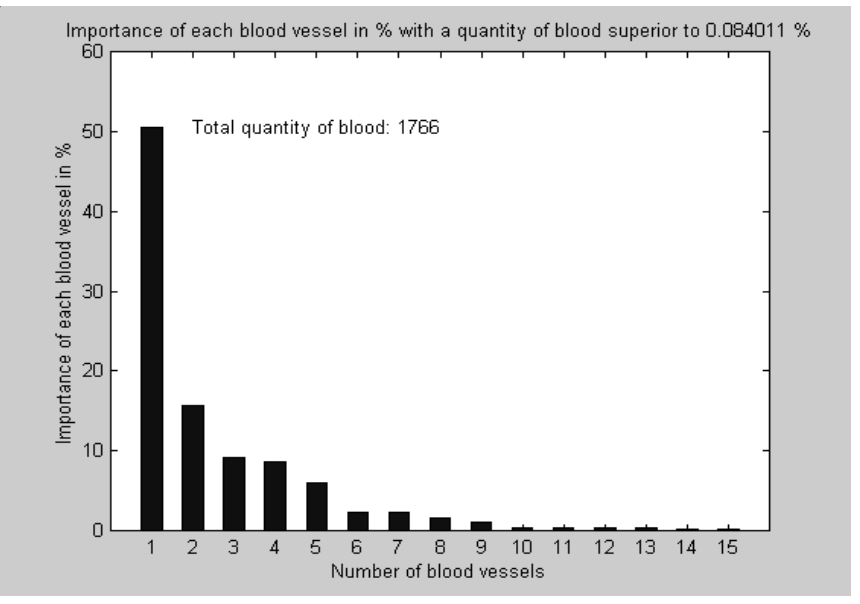

Fig. 11: Quantitative and automated estimation of blood volume around the follicle

exists between follicular growth and $\mathrm{E}_{2}$ level, ultrasound was introduced for follicular growth, which previously had been so indirectly evident. Ultrasound correlated precisely with $\mathrm{E}_{2}$ assays and with the number of mature follicles.

At the beginning of stimulation, information about the presence of a cyst or follicle like structure will modify our clinical approach to stimulation or cycle cancellation. In the middle of the follicular phase during $\mathrm{COH}$, ultrasonographic evaluation of follicle growth and number will influence gonadotropin dose in the next days or the cancellation of the cycle if no response is documented. Monitoring of follicle growth and its vascularization at the end of $\mathrm{COH}$ could certainly increase the quality of the retrieved oocytes considerably.

Maturity of the oocyte is closely associated with the size of the follicles and the serum estradiol levels. Commonly, the first serum estradiol level is measured after 3 to 5 days to determine whether the dose of the chosen stimulatory drug is optimal. Afterwards, levels of estradiol and transvaginal ultrasono- graphic scans are carried out every 1 to 3 days (interval between measurements depends upon clinical findings). The goal is to obtain at least two follicles measuring 17 to $18 \mathrm{~mm}$ in mean diameter, optimally accompanied by a few others with mean diameter of 14 to $16 \mathrm{~mm}$, and to obtain the serum estradiol level consistent with the overall size and maturity of the cohort, i.e. the serum estradiol level of app. $200 \mathrm{pg} / \mathrm{ml}$ per follicle measuring $\geq \mathrm{mm}$. These threshold values are just a rough guideline, because measurements of follicles vary among observers and estradiol assays vary in their characteristics and adequate ranges of values. That is why each IVF program must empirically establish its own thresholds.

The growing follicle matures and secretes increasing levels of estradiol $\left(E_{2}\right) . E_{2}$ affects the target organs and promotes proliferation of the endometrium, increasing its thickness. Clear associations between the diameter of the dominant follicle and the levels of $E_{2}$, and between the levels of $E_{2}$ and endometrial thickness inspired some authors to try using ultrasound as the only monitoring tool for IVF cycles. Another important reason that made this approach attractive was the economic benefit for the patient. In 1985 Nilson et al ${ }^{83}$ suggested that ultrasound alone is sufficient to estimate follicular maturity and hence the administration of hCG which determines ovulation. Vlaisavljevic et $a l^{84,85}$ advocate a simplification of ultrasound monitoring where $\mathrm{COH}$ is adjusted to the woman's needs. Major concerns arising from this less intensive approach are its possible negative effect on the pregnancy rate and the possibility of ovarian hyperstimulation syndrome (OHSS) developing.

An OHSS is a condition of unknown etiology, with potentially life-threatening complications. They include renal failure, adult respiratory distress syndrome (ARDS), hemorrhage from ovarian rupture, and thromboembolism. The following factors increase the risk of developing ovarian hyperstimulation syndrome (OHSS): young age, low body weight, polycystic ovary syndrome (PCOS), higher doses of exogenous gonadotropins, high absolute or rapidly rising serum estradiol levels and previous episodes of OHSS. Caution is indicated when any of the following indicators for increasing risk of OHSS are present: rapidly rising serum estradiol levels; an estradiol concentration exceeding 2,500 pg/ml; and the emergence of a large number (more than 20 according to some authors) of intermediate sized follicles (10 to $14 \mathrm{~mm}$ ). ${ }^{86}$

The potential severity of OHSS is the main reason why many authors recommend intensive monitoring of IVF cycles with both determination of the $\mathrm{E}_{2}$ levels and ultrasound scanning. Daily ultrasound and estradiol monitoring remains essential for avoiding eventual OHSS. However, emphasizing the idiosyncratic nature of OHSS - which makes us incapable of avoiding this condition completely ${ }^{87}$-other authors think that intensive monitoring with measuring of $\mathrm{E}_{2}$ levels in addition to ultrasound scanning is justified only in case of high suspicion based on risk factors and clinical picture. ${ }^{4}$ In the retrospective 
study of Ben-Shlomo et al, ${ }^{88}$ the intensive monitoring protocol was compared to one using ultrasound scanning only. There was no difference in the duration of stimulation, the amount of gonadotropins used, the number of oocytes retrieved, fertilization rates and clinical pregnancy rates. Most importantly, the incidence of OHSS in the two approaches did not differ significantly.

At present, data that would help us accept one and abandon the other approach are insufficient. There is a clear need for additional investigation of this issue. Sufficient clinical suspicion for the development of OHSS requires the full attention of the attending physician and the introduction of preventive measures: withholding further gonadotropin stimulation ("coasting") and delaying hCG administration until the estradiol levels plateau or decrease. Administration of a lower dose of hCG or application of a GnRH agonist rather than hCG in the GnRH antagonist stimulation protocol; the use of exogenous progesterone for luteal phase support rather than supplemental doses of hCG; prophylactic IV administration of $25 \%$ albumin at the time of oocyte retrieval or puncture of all follicles from one ovary 12 hours after hCG administration followed by oocyte pickup of the opposite ovary 35 hours later ${ }^{89}$ are procedures suggestive of diminished frequency of OHSS, but there is not enough evidence to support such expectations.

Patients at risk of OHSS might benefit from in vitro maturation to avoid elevation of estradiol and gonadotropins that may trigger or worsen OHSS. Compared with aspiration of in vivo matured oocytes in follicles of preovulatory size, aspiration of immature oocytes from follicles of 5 to $10 \mathrm{~mm}$ in diameter is technically demanding. ${ }^{80,90}$

\section{REFERENCES}

1. Matijevic R, Grgic O. Predictive values of ultrasound monitoring of the menstrual cycle. Curr opin Obstetri Gynecol 2005;17(4):405-10.

2. Ekerhovd E, Fried G, Granberg S. An ultrasound-based approach to the assessment of infertility, including the evaluation of tubal patency. Best Pract Res Clin Obstet Gynaecol 2004;18(1):13-28.

3. Gourgeon A. Initiation of ovarian follicular growth: few facts and many hypothesis. In Filicori M, Flamingi C (Eds): The Ovary: Regulation, Dysfunction and Treatment. Excerpta Medica ICS 1006,1996; pp 3-12.

4. Fortune JE, Cushman RA, Wahl CM, Kito S. The primordial to primary follicle transition. Mol Cell Endocinol 2000;163:5360.

5. Erickson GF. Ovulation: Evolving Scientific and Clinical concepts (1st edn). New York: Springer-Verlag 2000; pp 3148.

6. Erickson GF, Shimasaki S. The role of the oocyte in folliculogenosis. Trends Endocrinol Metab 2000;163:61-6.
7. Gougeon A, Lefèvre B. Evolution of diameters of the largest healthy and atretic follicles during the human menstrual cycle. J Reprod Fertil 1983;69:497-502.

8. Gougeon A, Chainy GBN. Morphometric studies of small follicles in ovaries of women at different ages. J Reprod Fertil 1987;81:433-42.

9. Balakier H, Stronell RD. Color doppler assessment of folliculogenesis in in vitro fertilization patients. Fertil Steril 62:1211-16.

10. Gougeon A. Regulation of ovarian follicular development in primates: facts and hypotheses. Endocr Rev 1996;17(2):12155 .

11. Suh CS, Sonntag B, Erickson GF. The ovarian life cycle: a contemporary view. Rev Endocr Metab Disord 2002;3(1):512.

12. Bassett DL. The changes in the vascular pattern of the ovary of the albino rat during the estrous cycle. Am J Anat 1943;73:252292.

13. Sladkevicius P, Valentin L, Marsal K. Blood flow velocity in the uterine and ovarian arteries during the normal menstrual cycle. Ultrasound Obstet Gynecol 1993;3:199-208.

14. Van Blerkom J, Antczak M, Schrader R. The developmental potential of the human oocyte is related to the dissolved oxygen content of follicular fluid: association with vascular endothelial growth factor levels and perifollicular blood flow characteristics. Human Reprod 1997;12:1047-55.

15. Abulafia O, Sherer DM. Angiogenesis of the ovary. Am J Obstet Gynecol 2000;182:240-6.

16. Pache TD, Wladimiroff JW, de Jong FH, Hop WC, Fauser BCJM. Growth patterns of non dominant ovarian follicles during the normal menstrual cycle. Fertil Steril 1990;54:638-42.

17. Bakos O, Lundkvist O, Wide L, Bergh T. Ultrasonographical and hormonal description of the normal ovulatory menstrual cycle. Acta Obstet Gynecol Scand 1994;73:790-6.

18. Kratochwil A, Urban G, Fridrich G. Ultrasonic tomography of the ovary. Ann Chir Gynecol Fenn 1972;61:211-4.

19. Hackelöer BJ, Nitche-Debelstein S, Daume E,Sturm G, Bucholz R. Ultraschalldarstellung von Ovarveränderungen bei Gonadotropin Stimulierung. Geburtshilfe Frauenheild 1977; 37,185 .

20. Fleisher AC, Darnell J, Rodier J, Lindsay A, James AE. Sonographic monitoring of ovarian follicular development. J Clin Ultrasound 1981;9:275-80.

21. O'Herlihy C, de Crespigny L. Robinson HP. Monitoring ovarian follicular development with real-time ultrasound. Br J Obstet Gynecol 1980;87;613-8.

22. Quenan JT, O'Brein GD, Bains LM, Simpson J, Collins WP, Campbell S. Ultrasound scanning of ovaries to detect ovulation in women. Fertil Steril 1980;34:99-105.

23. Gore MA, Nayudu PL, Vlaisavljevic V, Thomas N. Prediction of ovarian cycle outcome by follicular characteristics, stage 1 . Hum Reprod 1995;10(9):2313-9. 
24. Gore MA, Nayudu PL, VlaisavljeviæV. Attending dominance in vivo: distinguishing dominant from challenger follicles in humans. Human Reprod 1997;12(12):2741-7.

25. Bomsel-Helmreich O, Al-Mufti W. Ultrasonography of normal and abnormal follicular development. In Jaffe R, Pierson RA, Abramowicz JS (Eds): Imaging in infertility and reproductive endocrinology. 1st ed. Philadelphia: JB Lippincott; 1994; pp 117-28.

26. Pashe TD, Wladimiroff JD, de Jong FH, Hop WC, Fauser BC. Growth patterns of non-dominant ovarian follicles during normal menstrual cycle. Fertile Steril 1990;54:638-42

27. Nayudu P. Relationship of constructed follicle growth patterns in stimulated cycles to outcome after IVF. Human Reprod 1991;6:465-71.

28. Vlaisavljeviæ V. Analysis of follicular growth in conceivers and nonconceivers after intrauterine insemination. Gynecol Perinatol 1995;4:49-51.

29. Chikazawa K, Araki S, Tamada T. Morphological and endocrinological studies on follicular development during the human menstrual cycle. J Clin Endocrinol Metab 1986;62:30513.

30. Assey RJ, Hyttel P, Greve T, Purwantara B. Oocyte morphology in dominant and subordinate follicles. Mol Reprod Dev 1994;37:335-44.

31. Vlaisavljeviæ V, Reljiè M, Lovrec Gavriæ V, Kovaèiè B. Comparable effectiveness using flexible single-dose $\mathrm{GnRH}$ antagonist (cetrorelix) and single-dose long acting GnRH agonist (goserelin) protocol for IVF cycles-a prospective, randomized study. Reprod Biomed Online 2003;7:301-8.

32. Vlaisavljeviæ V, Kovaèiè B, Reljiè M, Gavriæ Lovrec V. Three protocols for monitoring follicle development in 587 unstimulated cycles of in vitro fertilization and intracytoplasmic sperm injection. A comparison. J Reprod Med 2001:46:892-8.

33. Bourne TH, Jurkovic D, Waterstone $\mathbf{J}$, et al. Intrafollicular blood flow during human ovulation. Ultrasound Obstet Gynecol 1991;5:53-9.

34. Ecochard R, Marret H, Rabilloud, et al. Sensitivity and specificity of ultrasound indices of ovulation in spontaneous cycles. Eur J Obstet Gynecol Reprod Biol 2000;91:59-64.

35. Pearlstone AC, Surrey ES. The temporal relation between the urine LH surge and sonographic evidence of ovulation: determinants and clinical significance. Obstet Gynecol 1994;83:184-7.

36. Campbell S, Bourne T, Waterstone J, Reynolds K, Crayford T, Jurkovic D, Okokon E, Collins W. Transvaginal color blood flow imaging of the preovulatory follicle. Fertil Steril 1993;60:433-8.

37. Kupesic S, Kurjak A. Uterine and ovarian perfusion during the periovulatory period assessed by transvaginal color doppler. Fertil Steril 1993;60:439-43.

38. Brannstrorm M, Zackrisson U, Hagstroom HG, et al. Blood flow indices as measured by color doppler ultrasonography in different regions of the human periovulatory follicle. Fertil Steril 1998;69:435-42.
39. Jarvela IY, Sladkevicius P, Kelly S, Ojha K, Nargund G, Campbell S. Three-dimensional sonographic and power Doppler characterization of ovaries in late follicular phase. Ultrasound Obstet Gynecol 2002;20(3):281-5.

40. Vlaisavljevic V, Reljic M, Gavric Lovrec V, Zazula D, Sergent $\mathrm{N}$. Measurement of perifollicular blood flow of the dominant preovulatory follicle using three-dimensional power Doppler. Ultrasound Obstet Gynecol. 2003;22(5):520-6.

41. Zeleznik AJ, Schuler HM, Reichert LE. Gonadotropin-binding sites in the Rhesus monkey ovary: role of the vasculature in the selective distribution of human chorionic gonadotropin to the preovulatory follicle. Endocrinology 1981;109:356-62.

42. Kranzfelder D, Maurer-Schultze B. Development of the perifollicular network. Autoradiographic and morphometric studies in the rabbit ovary. Eur J Obstet Gynecol 1989;30:16371.

43. Plachot M, Veiga A, Montagut J. Are clinical and biological parameters correlated with chromosomal disorder in early life: a multicenter study. Hum Reprod 1988;3:627-35.

44. Gaulden M. Maternal age effect: the enigma of Down syndrome and other trisomic conditions. Mutat Res 1992;296:69-88.

45. Padilla SL, Garcia JE. Effect of maternal age and number of in vitro fertilization procedures on pregnancy outcome. Fertil Steril 1989;52:270-3.

46. Toner JP, Philput CB, Jones GS, Muasher SJ. Basal folliclestimulating hormone level is a better predictor of in vitro fertilization performance than age. Fertil Steril 1991;55:78491.

47. Tan SL, Rayston P, Campbell S, Jacobs HS, Betts J, Mason B, et al. Cumulative conception and livebirth rates after in vitro fertilisation. Lancet 1992;339:1390-4.

48. Check JH, Lurie D, Callan C, Baker A, Benfer K. Comparison of the cumulative probability of pregnancy after in vitro fertilization-embryo transfer by infertility factor and age. Fertil Steril 1994;61:257-61.

49. Syrop CH, Willhoite A, Voorhis BJ. Ovarian volume: a novel outcome predictor for assisted reproduction. Fertil Steril 1995; 64:1167-71.

50. Lass A, Skull J, McVeigh E, Margara R, Winston RML. Measurement of ovarian volume by transvaginal sonography before ovulation induction with human menopausal gonadotropin for in vitro fertilization can predict poor response. Hum Reprod 1997;12:294-7.

51. Pellicer A, Ardiles G, Neuspiller F, Remohi J, Simon C, BonillaMusoles F. Evaluation of ovarian reserve in young low responders with normal basal levels of follicle-stimulating hormone using three-dimensional ultrasonography. Fertil Steril 1998;70(4):671-5.

52. Sharara FI, McClarmrock HD. The effect of aging on ovarian volume measurements in infertile women. Obstet Gynecol 1999;94:57-60.

53. Sharara FI, McClarmrock HD. Use of microdose GnRH agonist protocol in women with low ovarian volumes undergoing IVF. Hum Reprod 2001;16:500-3.

54. Kupesic S, Kurjak A, Bjelos D, Vujisic S. Three-dimensional ultrasonographic ovarian measurements and in vitro fertilisation outcome are related to age. Fertil Steril 2003;79(1):190-7. 
55. Wu MH, Tang HH, Hsu CC, Wang ST, Huang E. The role of three-dimensional ultrasonographic images in ovarian measurements. Fertil Steril 1998;69:1152-5.

56. Adams J, Franks S, Polson DW, et al. Multifollicular ovaries: clinical and endocrine features and response to pulsatile gonadotropin releasing hormone. Lancet 1985;ii:1375-9.

57. Zaidi J, Campbell S, Pitroff R, Kyei-Mensah A, Shaker A, Jacobs HS, Tan SL. Ovarian stromal blood flow in women with polycystic ovaries - a possible new marker for diagnosis? Hum Reprod 1995;6:191-8.

58. The Rotterdam ESHRE/ASRM-sponsored PCOS consensus workshop group. Revised 2003 consensus on diagnostic criteria and long term health risk related to polycystic ovary syndrome (PCOS). Human Reprod 2004;19:41-7.

59. Ng EH, Tang OS, Ho PC. The significance of the number of antral follicles prior to stimulation in predicting ovarian response in an IVF programme. Hum Reprod 2000;15:1937-42.

60. Chang MY, Chiang CH, Hsieh TT, Soong KY, Hsu KH. Use of antral follicle count to predict the outcome of assisted reproduction technologies. Fertil Steril 1998;69:505-10.

61. Kupesic S, Kurjak A. Predictors of IVF outcome by threedimensional ultrasound. Hum Reprod 2002;17(4):950-5.

62. Engmann L, Sladkevicius P, Agrawal R, Bekir JS, Campbell S, Tan SL. Value of stromal blood flow velocity measurement after pituitary suppression in the prediction of ovarian responsiveness and outcome of in vitro fertilization treatment. Fertil Steril 1999;71:22-9.

63. Nagrund G, Bourne T, Doyle P, Parsons J, Cheng W, Campbell $\mathrm{S}$, Collins W. Associations between ultrasound indices of follicular blood flow, oocyte recovery and preimplantation embryo quality. Hum Reprod 1996;11:109-13.

64. Balakier H, Stronell RD. Color Doppler assessment of folliculogenesis in in vitro fertilization patients. Fertil Steril 1994;62:1211-6.

65. Tekay A, Martikainen H, Jouppila P. Blood flow changes in uterine and ovarian vasculature and predictive value of transvaginal pulsed colour Doppler ultrasonography in an in vitro fertilization programme. Hum Reprod 1995;10(3):68893.

66. Coulam CB, Goodman C, Rinehart JS. Colour indices of follicular blood flow as predictors of pregnancy after in vitro fertilization and embryo transfer. Hum Reprod 1999;14(8):197982.

67. Collins W, Jurkovic D, Bourne T, Kurjak A, Campbell S. Ovarian morphology, endocrine function and intrafollicular blood flow during the periovulatory period. Hum Reprod 1991;6(3):31924.

68. Zaidi J, Collins W, Campbell S, Pitroff R, Tan SL. Blood flow changes in the intraovarian arteries during the preovulatory period: relationship to the time of the day. Ultrasound Obstet Gynecol 1996;7:135-40.

69. Järvelä IY, Sladkevicius P, Kelly S, Ojha K, Campbell S, Nagrund G. Quantification of ovarian power Dopppler signal with three- dimensional ultrasonography to predict response during in vitro fertilization. Obstet Gynecol 2003;102(4):816-22.

70. Paulson RJ. Natural cycle in vitro fertilization. Infertil Reprod Med Clin North Am 1993;4:653-65.

71. Fahy UM, Cahill DJ, Wardle PG, Hull MGR. In vitro fertilization in completely natural cycles. Hum Reprod 1995;10(3):572-5.

72. Vlaisavljevic V, Gavric V, Kovacic B. In vitro fertilization in natural cycles: Maribor experience. The world congress on in vitro fertilization and assisted reproduction held in Vienna, Austria, 1995 April 3-7. Aburumich A, Bernat E, Dohr G, Feichtinger W, Fischl F, Huber J, Mueller E, Szalay S, Urdl W, Zech H (Eds): Bologna: Monduzzi Editore: 1995;573-5.

73. Lenton EA, Woodward B. Controversies in assisted reproduction. Natural vs. stimulated cycles in IVF: Is there a role for IVF in natural cycle? J Assist Reprod Genet 1993;10: 406-8.

74. Foulot H, Ranoux C, Dobuisson JB, Rambaud FX, Poirot C. In vitro fertilization without ovarian stimulation: a simplified protocol applied in 80 cycles. Fertil Steril 1989;52:617-21.

75. Ramsewak S, Cooke I, Li T, Kumar A, Monks N Lenton E. Are factors that influence oocyte fertilization also predictive? An assessment of 148 cycles of in vitro fertilization without gonadotropin stimulation. Fertil Steril 1990;54:470-4.

76. Paulson R, Sauer M, Francis M, Macaso T, Lobo R. In vitro fertilization in unstimulated cycles: the University of Southern California experience. Fertil Steril 1992;57:290-3.

77. Paulson RJ, Sauer MV, Francis M, Macaso M, Lobo R. Factors affecting pregnancy success of human in vitro fertilization in unstimulated cycles. Hum Reprod 1994;9:1571-5

78. Reljiè M, Vlaisavljeviæ V. The preovulatory serum estradiol pattern in natural IVF/ICSI cycles. J Assist Reprod Genet 1999; 16:535-9.

79. Toma•eviè T, Geršak K, Meden-Vrtovec H, Drobniè Š, Veble A, Valenèiè B, Kermavner L, Virant Klun I, Zemva Z. Clinical parameters to predict the success of in vitro fertilization-embryo transfer in the natural cycle. Assisted Reproduction 1999;9:14956.

80. Vlaisavljeviæ V, Kovaèiè B, Reljiè M, Gavriæ Lovrec V, Èi•ek Sajko M. Is there any benefit from the culture of a single oocyte to a blastocyst-stage embryo in unstimulated cycles? Hum Rreprod 2001;16:101-5.

81. Tan SL, Zaidi J, Campbell S, Doyle P, Collins W. Blood flow changes in the ovarian and uterine arteries during normal menstrual cycle. Am J Obstet Gynecol 1996;175(3):625-31.

82. Gavriæ Lovrec VG, Vlaisavljevic V, Reljic M. Dependence of the in-vitro fertilization capacity of the oocyte on perifollicular flow in the preovulatory period of unstimulated cycles. Wien Klin Wochenschr. 2001;113[Suppl 3]:21-6.

83. Nilson L, Wikland M, Hamburger L, Hillensjo T, Chari S, Sturm G, Daume E. Simplification of the method of in vitro fertilization: sonographic measurements of follicular diameter as a sole index of follicular maturity. J In Vitro Fert Emryo Transf 1985;2:17. 
84. Vlaisavljeviæ V, Kovaèiè B, Gavriæ V. In vitro fertilization program based on programmed cycles monitored by ultrasound only. Int J Gynecol Obstet 1992;39:227-31.

85. Vlaisavljeviæ V, Kovaèiè $\mathrm{B}$, Gavriæ Lovrec V, Reljiè M. Simplification of the clinical phase of IVF and ICSI treatment in programmed cycles. Int J Gynecol Obstet 2000;69:135-42.

86. Practice Committee of American Society for Reproductive Medicine, Birmingham, Alabama, USA. Ovarian hyperstimulation syndrome. Fertil Steril 2003; 80(5):1309-14.

87. Braude P, Rowell P. Assisted conception. III-problems with assisted conception. BMJ 2003;327(7420):920-3.
88. Ben-Shlomo I, Geslevich J, Shalev E. Can we abandon routine evaluation of serum estradiol levels during controlled ovarian hyperstimulation for assisted reproduction? Fertil Steril 2001;76:300-3.

89. Toma•eviè T, Meden Vrtovec H. Early timed follicular aspiration prevents severe ovarian hyperstimulation syndrome. J Assist Reprod Genet 1996;13:282-6.

90. Vlaisavljeviæ V, Èi•ek Sajko M, Kovaèiè B. Multinucleation and cleavage of embryos derived from in vitro matured oocytes. Fertil Steril 2006;86:487-9. 